\title{
Biomarkers of Inflammation in Inflammatory Bowel Disease: How Long before Abandoning Single-Marker Approaches?
}

\author{
Gabriele Dragoni ${ }^{a, b, c}$ Tommaso Innocentia, ${ }^{b} \quad$ Andrea Gallib \\ aIBD Referral Center, Gastroenterology Department, Careggi University Hospital, Florence, Italy; bastroenterology \\ Research Unit, Department of Experimental and Clinical Biochemical Sciences "Mario Serio", University of Florence, \\ Florence, Italy; 'Department of Medical Biotechnologies, University of Siena, Siena, Italy
}

\section{Keywords}

Accuracy · Biomarkers · Combination · Inflammatory bowel disease $\cdot$ Precision medicine

\begin{abstract}
Background: Inflammatory bowel disease (IBD) is a chronically relapsing disease with a continuous need for proactive monitoring to decide appropriate treatments and follow-up strategies. To date, gastrointestinal endoscopy with histologic examination of biopsies and contrast-enhanced imaging are mandatory techniques for the diagnosis and the activity assessment of IBD. Summary: In recent decades, many research efforts in the IBD field have been placed on finding non-invasive and reliable biomarkers of disease burden that can be easily tested in body fluids without impacting the quality of life of patients. Unfortunately, the ideal biomarker is yet to be discovered and recent studies have investigated the possibility to increase the accuracy of such measurements by combining different markers. In this review, we provide an update about the current knowledge on biomarkers of intestinal inflammation in IBD, focussing on disease diagnosis, correlation with endoscopic findings, and
\end{abstract}

prediction of relapse. We also summarize composite scores of clinical and laboratory markers that have been recently proposed in various scenarios of disease activity. Key Messages: To date, only C-reactive protein and faecal calprotectin can be considered reliable markers of disease activity with demonstrated utility in IBD management. The combination of different parameters has recently shown higher accuracy and might substitute single-marker approaches in the future of research and clinical practice.

(c) 2020 S. Karger AG, Base

\section{Introduction}

Inflammatory bowel disease (IBD) refers to 2 chronic conditions of the digestive tract with a strong impact on the quality of life of the affected individuals, that is, ulcerative colitis (UC) and Crohn's disease (CD). The aetiology and pathogenesis of IBD are still unclear, with the most likely trigger being a dysregulated immune response to the commensal gut flora and external insults in a genetically predisposed individual [1-3]. karger@karger.com

www.karger.com/ddi

Karger $\stackrel{2}{*}$ (c) 2020 S. Karger AG, Base

(n)

\footnotetext{
Gabriele Dragoni

Department of Experimental and Clinical Biochemical Sciences "Mario Serio" University of Florence, Viale Pieraccini 6

IT-50139 Firenze (Italy)

gabriele.dragoni@unifi.it
} 


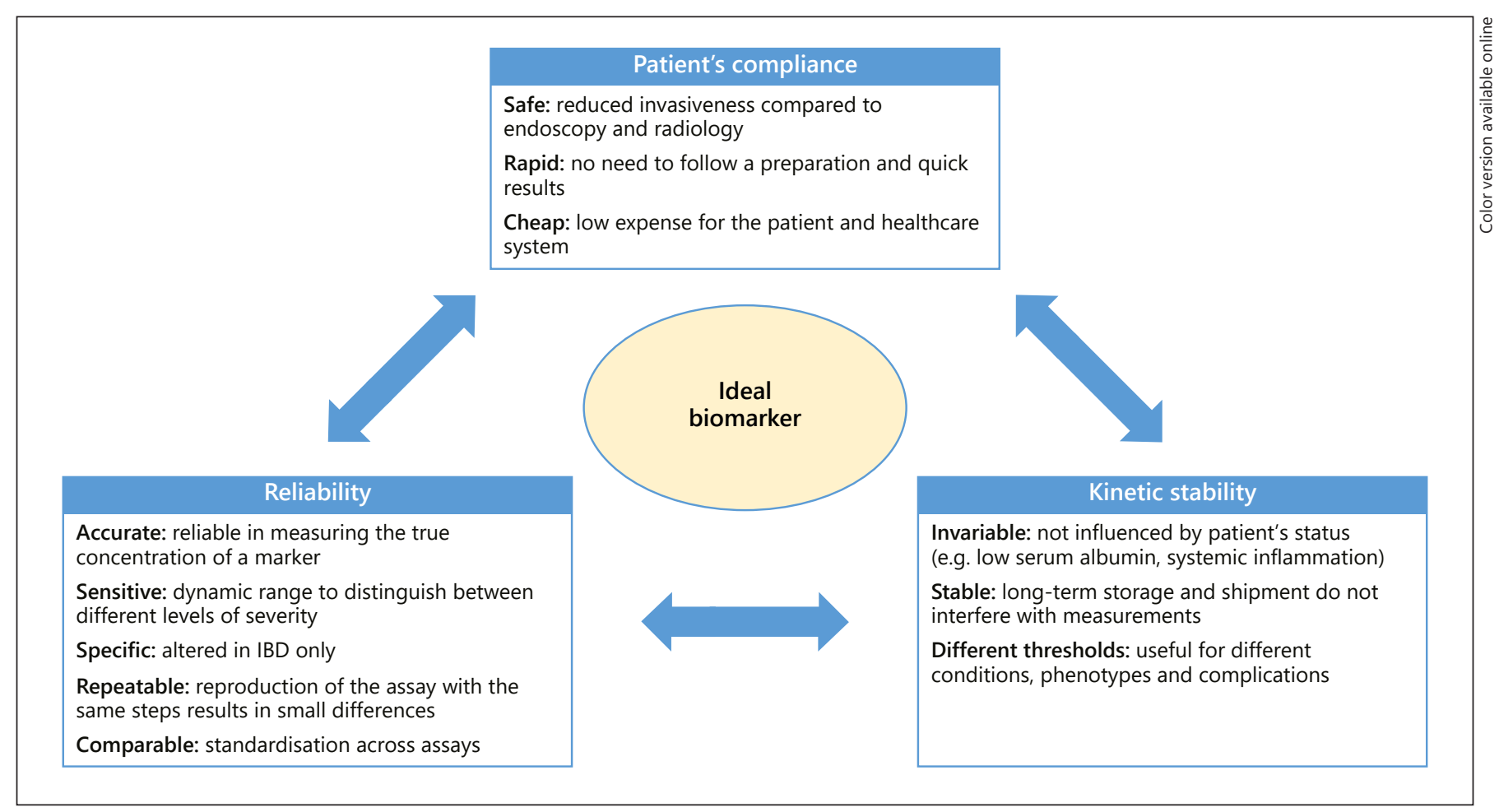

Fig. 1. Characteristics of the ideal biomarker (adapted from the work by Sands [11]). IBD, inflammatory bowel disease.

Gastrointestinal endoscopy with subsequent histologic evaluation of biopsies is required for the diagnosis and scoring of mucosal inflammation, and cross-sectional imaging provides additional information on the extent of $\mathrm{CD}$ in the small bowel, which is technically unreachable by the endoscope [4]. Nevertheless, patients are reluctant to undergo invasive endoscopic follow-ups and both these techniques highly impact the healthcare finances if we consider the need to routinely re-assess a disease with chronic intermittent behaviour. Consequently, an urgent topic of investigation in recent decades has been the study of accurate biomarkers of disease activity to reduce costs and increase patients' compliance.

\section{The Ideal Biomarker}

The ability to discriminate between active and inactive disease with non-invasive tools is a diagnostic goal in many medicine fields. In IBD, research has mainly focussed on the identification of reliable biomarkers of intestinal inflammation to guide treatment management and predict disease course.

Approximately 20 years ago, the United States National Institute of Health defined a biomarker as "a characteristic that is objectively measured and evaluated as an indication of normal biologic processes, pathogenic processes, or pharmacologic responses to a therapeutic intervention" [5]. The ideal biomarker should satisfy 3 different domains: patient compliance, reliability for the disease, and kinetic stability (Fig. 1). Based on these premises, several issues have been raised in the field of IBD research. First, IBD is a spectrum of 2 different entities (UC and CD) with an unclear "grey area" of unclassified patients and a modification of diagnosis in $5-10 \%$ of cases $[6,7]$. Second, the overlap between inflammation and fibrosis and the different possible characteristics of the disease (extent, activity, and phenotype and related complications) further complicate the scenario. Therefore, although some markers of inflammation are currently used in clinical practice, the discovery of an ideal biomarker seems unattainable and the combination of different tests is rising as more than an alternative to the classic inflammatory markers.

\section{Biomarkers of Intestinal Inflammation}

The natural history of IBD includes flares of acute inflammation and periods of quiescence associated with mucosal healing, which is currently the main therapeutic 
Table 1. Biomarkers correlated with intestinal inflammation [79,94,120-148]

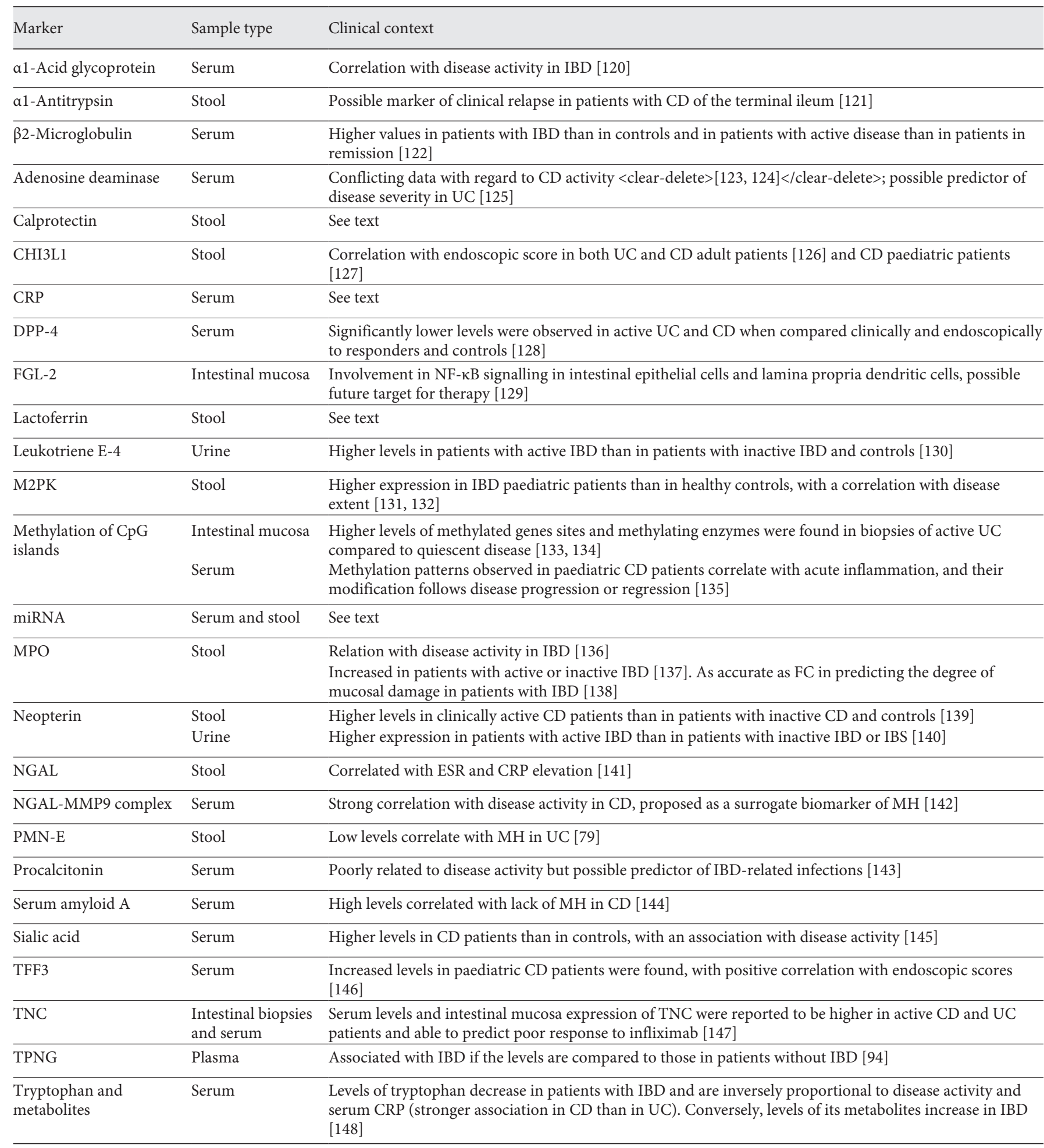

CD, Crohn's disease; CDAI, Crohn's Disease Activity Index; CDEIS, Crohn's Disease Endoscopic Index of Severity; CHI3L1, chitinase 3-like-1; CpG, cytosine-phosphate-guanine; CRP, C-reactive protein; DPP-4, dipeptidyl peptidase 4; ESR, erythrocyte sedimentation rate; FGL-2, fibrinogen-like protein 2;IBD, inflammatorybowel disease; M2PK, M2-pyruvatekinase; $\mathrm{MH}$, mucosal healing; MMP9, matrix metalloproteinase-9; MPO, neutrophil myeloperoxidase; NGAL, neutrophil gelatinase B-associated lipocalin; NF- $\mathrm{BB}$, nuclear factor $\kappa \mathrm{B}$; PMN-E, polymorphonuclear elastase; TFF3, trefoil factor 3; TPNG, total plasma N-glycomes; UC, ulcerative colitis. 
goal [8]. Unfortunately, gastrointestinal endoscopy with biopsies is the only gold standard to assess deep histologic remission, but it is an invasive and expensive technique. The recent proposal to introduce transmural healing for $\mathrm{CD}$ as an additional therapeutic endpoint further complicates IBD assessment [9]. As a consequence, it is crucial to find surrogate biomarkers of clinical, endoscopic, histologic, and transmural activity to increase patient compliance and the cost-effectiveness of IBD management.

The clinical settings in which biomarkers of inflammation could be used are various. In the diagnostic field, a marker of inflammation burden should be able to discriminate IBD from functional disorders, such as irritable bowel syndrome (IBS), otherwise clinically indistinguishable in many cases [10], and assess disease activity. Moreover, the ability to monitor the efficacy of a medical treatment and predict surgical outcomes (risk of colectomy in $\mathrm{UC}$ and postsurgical recurrence in CD) is additional unmet needs [11].

In general, stool markers are more likely than blood markers to reflect the degree of intestinal inflammation due to direct contact with the mucosal environment, whereas blood markers often increase for different reasons, and local inflammation does not always correspond to a detectable systemic inflammatory response. Many data on potential biomarkers of intestinal inflammation have accumulated in recent years (Table 1). Nevertheless, serum C-reactive protein (CRP) and faecal calprotectin (FC) are still the most reliable and routinely used markers of disease activity.

\section{C-Reactive Protein}

Serum CRP is an acute-phase reactant that is widely accepted as a general inflammatory marker in the IBD field. As it is a non-specific biomarker, CRP can increase in several medical conditions other than IBD, for example, systemic infections and extraintestinal inflammation [12]. On the other hand, approximately $15 \%$ of the healthy population $[13,14]$ and as high as $20-25 \%$ of CD patients [12] do not have a CRP response, which is a cause of falsenegative results.

CRP has a high sensitivity for discriminating between IBD and IBS, as reported in a meta-analysis of 12 prospective diagnostic cohort studies where CRP levels in the range of normality resulted in a $\leq 1 \%$ probability of having IBD [15]. Its levels are often related to the inflammatory burden of UC and CD $[12,16]$, although a poor correlation is sometimes reported for UC, especially in the setting of mild ulcerative proctitis $[16,17]$. Accordingly, many studies have shown that extensive transmural inflammation in CD presents higher CRP levels than mildto-moderate mucosal inflammation in UC [18-20]. On the other hand, CRP $>45 \mathrm{mg} / \mathrm{L}$ combined with a stool frequency between 3 and 8 per day on day 3 (known as the Oxford Criteria) predicts the occurrence of colectomy in $85 \%$ of patients with acute severe UC during hospitalization [21], despite recent data have partially reconsidered these results [22].

At the endoscopic level, CRP has been demonstrated to correlate with disease activity, with levels within the normal range in cases of negative ileocolonoscopy [16, 17]. However, in a recent prospective study on $186 \mathrm{pa}$ tients with UC, Sonoyama et al. [17] reported that serum CRP was not as strongly related to the Mayo Endoscopic Score as FC and no correlation could be observed between CRP and ulcerative proctitis.

With regard to disease monitoring, CRP has been shown to predict clinical relapse and therapy failure in both CD and UC [23-25]. Particularly, a serum CRP of $>5 \mathrm{mg} / \mathrm{L}$ at week 22 after the initiation of infliximab (IFX) was found to be predictive of loss of response in patients who were in clinical remission at week 14 (HR: 2.5; 95\% CI: $1.16-5.26$; $p=0.019$ ) [25]. In addition, in a large retrospective study involving 1,189 patients with $\mathrm{CD}$, high serum CRP was found to be predictive of a low retention rate of adalimumab treatment over a 4 -year period of follow-up [26].

On the other hand, conflicting data have been published regarding the correlation between $\mathrm{CRP}$ and $\mathrm{CD}$ post-operative recurrence (POR). A randomized controlled trial of 24 patients reported a poor sensitivity (25\%) for endoscopic POR at 1 year [27]. Conversely, in a small study $(n=12)$ of IFX withdrawal after 3 years of clinical and endoscopic remission after surgery, CRP levels correlated with POR relapse and subsequent response after resumption of therapy [28]. Moreover, another study reported only a very weak although statistically significant difference between patients with POR and patients with endoscopic remission after a median of 7 months after surgery [29].

Therefore, the settings in which CRP was demonstrated to be mostly reliable are the differential diagnosis between IBS and IBD, the transmural inflammation of CD, the endoscopic activity of extensive and left-sided UC, and the monitoring of disease relapse. Conversely, CRP accuracy in the contexts of ulcerative proctitis and the prediction of $\mathrm{POR}$ in $\mathrm{CD}$ is rather low and other biomarkers should be preferably considered. 


\section{Faecal and Serum Calprotectin}

FC is the other fundamental inflammatory biomarker currently used to assess diagnosis and monitor response to treatment in $\operatorname{IBD}[12,30]$. Calprotectin is predominantly present in neutrophil granules and has an antimicrobial function $[31,32]$. Although it is found in various body fluids, its concentration in faeces is 6 times higher than that in blood in healthy individuals [33]. In particular, FC levels increase in patients with active IBD [34] and are correlated with neutrophil margination in the intestinal mucosa [35]. Despite a certain level of intra-individual variability when samples are collected at different timepoints over the course of the same day [36], its use has been widely accepted in clinical practice [4].

In most laboratories, the upper normal limit is set at $50 \mu \mathrm{g} / \mathrm{g}$, consistent with the results of a meta-analysis of 1,062 patients, in which it was found that a patient with IBS-like symptoms and a FC level of $<40 \mu \mathrm{g} / \mathrm{g}$ had a $1 \%$ or less chance of having IBD [15]. However, in general gastroenterology, this marker lacks specificity, as it can increase in many other intestinal conditions, such as coeliac disease, colon cancer, diverticulitis, use of anti-inflammatory drugs, and intestinal infections [37]. Furthermore, it is important to know the factors that can influence the test and reduce its sensitivity and specificity [38].

FC has shown a solid correlation with endoscopic activity in IBD. In a recent meta-analysis of 25 eligible studies that examined IBD endoscopic activity in association with FC, the authors reported a pooled sensitivity of $85 \%$ and a specificity of $75 \%$ in diagnosing active IBD [39]. When UC and CD were considered separately, the same meta-analysis revealed a better performance in UC patients (pooled sensitivity 87.3 vs. $82.4 \%$; specificity 77.1 vs. $72.1 \%$ ). A possible explanation for these findings lies in the conflicting results of FC accuracy when considering $\mathrm{CD}$ patients with isolated ileal disease [40-43]. Accordingly, in a study of 68 UC patients, it has been reported a strong correlation of FC levels with disease extent $(p=0.006)$, Mayo endoscopic score $(p=0.001)$, and Nancy histologic index $(p<0.001)$ [44].

The aforementioned Nancy index and the Geboes score are 2 validated histologic scores of disease activity developed for UC $[45,46]$. Defining histologic remission with a Geboes score of $<3.1$ or a Nancy score of $\leq 1$, a correlation between low levels of FC $(<60-100 \mu \mathrm{g} / \mathrm{g})$ and histologic remission was demonstrated [44, 47]. Moreover, Theede et al. [48] found that levels of FC lower than 40.5 $\mu \mathrm{g} / \mathrm{g}$ are able to predict histologic remission with a sensitivity and a negative predictive value of $100 \%$, despite the utilization of a non-validated score. Likewise, elevated FC values (ranged $72-250 \mu \mathrm{g} / \mathrm{g}$ ) showed to predict histologic inflammation in clinically silent patients in more recent studies [49-51]. Recently, a systematic review including 12 studies and 1,168 patients confirmed the correlation between FC and histologic activity, although validated cutoff levels and more prospective studies using validated scores are needed to overcome the heterogeneity of current literature [52].

Regarding disease monitoring, FC has been demonstrated to predict clinical relapse both in UC and in CD [53-57]. Importantly, a tight control of consecutive FC levels, as other inflammatory biomarkers, has shown to be superior to clinical assessment only and should be always recommended [58]. In addition, a recent large prospective study involving 185 clinically quiescent UC patients demonstrated that FC cutoffs of $\geq 170 \mu \mathrm{g} / \mathrm{g}$ and $\geq 135 \mu \mathrm{g} / \mathrm{g}$ were able to predict endoscopic and histologic activity, respectively [50].

FC has also a role in predicting the response to treatment. In 2006, Kolho et al. [59] noticed that children with IBD treated with glucocorticoids experienced a decrease in FC levels, but often not below $100 \mu \mathrm{g} / \mathrm{g}$. In the last few years, many data have accumulated on the capability of FC to predict the response to mesalamine, immunosuppressants, and biological treatments. For instance, dose intensification of mesalamine resulted in significant decrease of FC levels in UC patients in clinical remission despite elevated FC [60]; in the same study, patients with baseline FC $\geq 200 \mu \mathrm{g} / \mathrm{g}$ showed a higher risk of relapse [60]. In a study involving $88 \mathrm{CD}$ patients on azathioprine, FC levels were found to be strongly linked to thiopurine metabolite concentration: in patients with 6-tioguanine concentrations within the therapeutic range (250-450 $\mathrm{pmol} / 8 \times 10^{8}$ red blood cells), FC was significantly lower than in patients with different levels of metabolite concentration [61]. A prospective study involving 53 patients with UC undergoing an induction cycle with infliximab showed that patients with a significant decrease in FC at week 2 were more likely to achieve endoscopic remission at week 10 [62]. In another prospective study, FC $<82$ $\mu \mathrm{g} / \mathrm{g}$ at week 14 predicted clinical remission within 12 months in $\mathrm{CD}$ patients treated with anti-TNF agents (sensitivity 93\%; specificity 75\%) [63]. A post hoc analysis of the GEMINI 1 trial (895 patients) showed that FC levels had higher reductions in patients with UC treated with vedolizumab than placebo; in particular, an absolute FC concentration of $\leq 150 \mu \mathrm{g} / \mathrm{g}$ was found to be the best predictor of clinical and endoscopic remission at week 6 [64]. Finally, Dulai et al. [65] confirmed the potential role of FC in monitoring clinical and endoscopic response in UC 
patients treated with an induction cycle of a biological agent or tofacitinib; the study showed that in patients who had resolution of rectal bleeding and normalization of stool frequency, an FC of $\leq 50 \mu \mathrm{g} / \mathrm{g}$ was able to rule out patients with moderate-to-severe endoscopic activity. Conversely, an FC of $\geq 200 \mu \mathrm{g} / \mathrm{g}$ was able to identify moderate-to-severe endoscopic activity in UC patients with persistent rectal bleeding and increased stool frequency [65].

In the context of monitoring for POR in $\mathrm{CD}$, conflicting results have been published in the last few years. In a cohort of $104 \mathrm{CD}$ patients with previous surgery, Lamb et al. [66] reported a moderate correlation between FC and post-operative Harvey-Bradshaw Index $(r=0.53, p<$ 0.001), whereas Yamamoto et al. [67] found no significant correlation between FC and Crohn's Disease Activity Index in a smaller cohort $(r=0.26, p=0.28)$. However, most evidence shows that FC is a more reliable marker than CRP for this purpose, at both clinical and endoscopic levels $[29,68-70]$.

Furthermore, a meta-analysis of $613 \mathrm{CD}$ patients monitored with FC after resection demonstrated a pooled sensitivity and specificity for POR prediction of $0.82(95 \%$ CI: 0.73-0.89) and 0.61 (95\% CI: 0.51-0.71), respectively [71]. As a result, in a survey amongst European gastroenterologists, $90 \%$ of respondents reported following CD patients with FC after a first negative colonoscopy [72]. Confidence for the application of this approach is the consequence of data showing the high negative predictive value (>90\%) of FC in this setting for levels $<100 \mu \mathrm{g} / \mathrm{g}$ [29, 68]. Interestingly, a recent systematic review studied the ability of FC to predict the development of IBD in patients with rheumatologic conditions, including ankylosing spondylitis and spondyloarthritis: endoscopic and histologic inflammation in the intestine was found in up to 80 and $100 \%$ of rheumatologic patients with increased FC levels, respectively [73].

Therefore, FC can be considered a reliable surrogate marker of endoscopic activity in IBD (especially in UC), a predictor of clinical and endoscopic relapse in UC, CD, and POR setting, and a useful tool for differentiating between IBS and IBD. On the other hand, the accuracy of detecting intestinal activity in CD patients with isolated ileal disease is significantly lower, as well as its specificity among several intestinal inflammatory conditions and between UC and CD in the context of new IBD diagnoses.

Among biological fluids, calprotectin is also particularly expressed in the blood. Serum calprotectin (SC) has been poorly studied, but the recent literature suggests its potential role as an inflammatory biomarker in IBD [74]. As an example, in the STORI trial, SC was significantly higher in patients with CD than in controls $(p<0.0001)$ and even higher in clinically active $C D$ than in quiescent disease $(p<0.0001)$, whereas no correlation was reported with endoscopic scores [75]. Therefore, it is likely that SC more accurately indicates a systemic inflammatory status rather than specific intestinal inflammation, resulting in a marginal role in IBD.

\section{Faecal Lactoferrin}

Faecal lactoferrin (FL) is another faecal biomarker that has shown results similar to FC [76]. Lactoferrin is an iron-binding $80-\mathrm{kDa}$ glycoprotein that is mainly released by neutrophils in the faeces after margination in the inflamed gut [77].

In a meta-analysis of 10 high-quality studies, FL showed pooled sensitivity and specificity values for assessing UC activity of 0.81 (95\% CI: $0.64-0.92$ ) and 0.82 (95\% CI: 0.61-0.93), respectively, and of 0.82 (95\% CI: $0.73-0.88)$ and 0.71 (95\% CI: 0.63-0.78) for CD, respectively [78]. In a post hoc analysis of a German clinical trial in patients with mild-to-moderate UC, a cutoff value of $11.9 \mu \mathrm{g} / \mathrm{g}$ for FL showed an area under the curve of $0.734(0.654-0.813, p<0.000)$, with a $70.2 \%$ diagnostic accuracy to detect sustained clinical remission and mucosal healing [79].

In an additional meta-analysis comparing CRP, FC, and FL among symptomatic IBD patients, FC and FL demonstrated higher reliability than CRP both in terms of pooled sensitivity ( 0.92 for FC, 0.88 for FL, and 0.49 for $\mathrm{CRP}$ ) and pooled specificity ( 0.82 for FC, 0.79 for $\mathrm{FL}$, and 0.73 for CRP) [76]. Again, a recent study has confirmed the superiority of FL when compared to CRP in terms of correlation with endoscopic activity [80].

Nevertheless, these presented data do not differ from the results already observed with FC and add no clinical utility when considered separately. A potential future use for FL is the combination of this marker with other serum and faecal measurements to increase the overall accuracy.

\section{MicroRNAs}

MicroRNAs (miRNAs) are a class of small, non-coding, negative regulators of gene expression with altered biogenesis due to the inflammatory response [81]. These markers are very attractive because of their stability in the extracellular environment and the ease and specificity at which they can be detected. Data in IBD are starting to accumulate, with identification of several miRNAs in the whole blood [82], serum [83-85], faeces [85, 86], and in- 
testinal tissues $[83,87-89]$ of patients with active IBD that differ from those in patients with quiescent disease and controls. Interestingly, miRNAs have been suggested as potential predictors of response to therapy since levels of let-7d and let-7e were significantly elevated at week 6 of the IFX induction regimen in patients achieving clinical remission [90].

Recently, $>800$ faecal miRNAs have been investigated in stool samples of patients with both UC and CD and compared to controls [86]. Findings suggest that patients with active $\mathrm{CD}$ and UC have distinct faecal miRNA profiles compared to non-IBD patients, particularly higher levels of miRNA-223 and miRNA-1246 [86]. Additional studies of larger cohorts with pooled-data meta-analyses and comparisons with other faecal markers such as FC are necessary to assess the real importance of miRNA in the evaluation of inflammation in IBD.

\section{Glycoproteomics}

Protein glycosylation is involved in the pathophysiology of many inflammatory diseases, and a central role has also been postulated in IBD [91-93]. In particular, some expression profiles of total plasma $\mathrm{N}$-glycomes have been recently associated with disease location, severity, need for potent treatment, and resection in a large multicentre study [94]. The ability of this profiling to discriminate non-IBD from IBD cases and active from nonactive disease might open a new investigational field for early diagnosis, assessment of activity, and prediction of response.

\section{Others}

In addition to CRP, IBD flares are associated with the increase in other positive acute-phase reactants and proinflammatory cytokines, such as erythrocyte sedimentation rate, platelet count, ferritin, haptoglobin, tumour necrosis factor $\alpha$, and coagulation and fibrinolysis factors, among others, and with a decrease in negative acutephase reactants, such as serum albumin, factor XII, and a2-macroglobulin [11, 95-97]. However, the vast majority of these serum biomarkers have shown conflicting associations with disease activity and have not demonstrated a clear superiority over CRP, probably because of their longer half-life.

Many other biomarkers have been tested in serum, faeces, and urine but have not entered clinical practice mainly due to unsatisfactory supporting evidence or the high costs of reproducibility. All biomarkers not discussed in the text are summarized in Table 1.

\section{Composite Biomarkers}

To date, FC has certainly shown the most robust evidence as a reliable single biomarker of IBD activity, reflecting better than CRP the degree of mucosal inflammation in the intestine [70, 98]. In last European recommendations for diagnostic assessment of IBD [4], an interval of 3 months for FC monitoring in patients with negative calprotectin ("target range") and of 1 month when above the threshold ("action range") has been proposed. Although very useful in guiding the management of clear cases, this approach presents 2 issues. First, the cutoff may vary between different IBD clinical contexts and assays provided by the manufacturers $[37,99]$. Second, despite the satisfying accuracy, there is still a grey zone ("uncertain range") that is difficult to be interpreted with FC alone. Therefore, a different and better performing strategy is needed, especially in patients with subclinical disease.

Composite biomarkers are "a combination of 2 or more biomarkers, which are combined by using a stated algorithm or approach to obtain a single interpretive readout" [100]. If we consider the complexity and heterogenicity of IBD, it is clear that a single marker cannot predict the activity of the disease in every single case and that the concept of "precision medicine" should be extended also to this field [101]. Data on composite scores of IBD activity have started to accumulate in the last few years (Table 2), and many more are expected to be published.

Most evidence comes from the combination of biomarkers with clinical symptoms, which is able to improve the predictive value of each item taken alone [102-108]. As an example, the integration of FC with CRP and clinical data (Simple Clinical Colitis Activity Index for UC and Harvey-Bradshaw Score for CD) has been reported to increase the yield of correct classification of IBD patients with "indefinite" FC levels between 100 and 250 $\mu \mathrm{g} / \mathrm{g}$ [103]. Likewise, in a cohort of CD patients treated with anti-TNF, the decrease in FC combined with CRP $<2.9 \mathrm{mg} / \mathrm{dL}$ and clinical remission at 12 weeks was the best predictor of corticosteroid-free remission at 52 weeks [104].

Another proposed score was the Utrecht Activity Index that combined the frequency of liquid stools in a day with CRP, FC, platelet count, and platelet mean volume with optimal results in terms of endoscopic activity prediction in CD patients [106]. However, in a recent systematic review on published composite biomarkers made of clinical and laboratory parameters, Brand et al. [109] reported that only 2 out of 7 analyzed indexes show lim- 


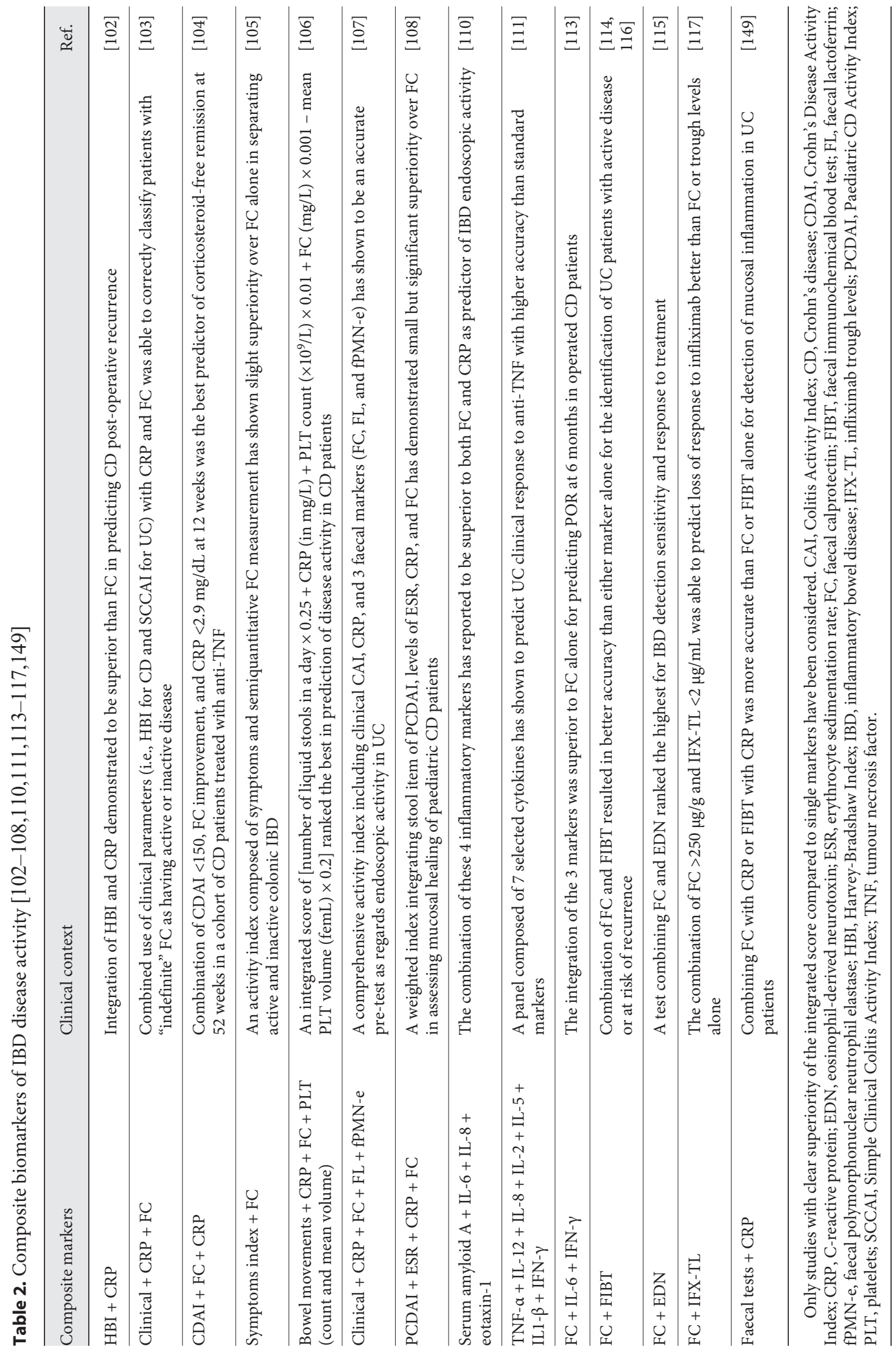




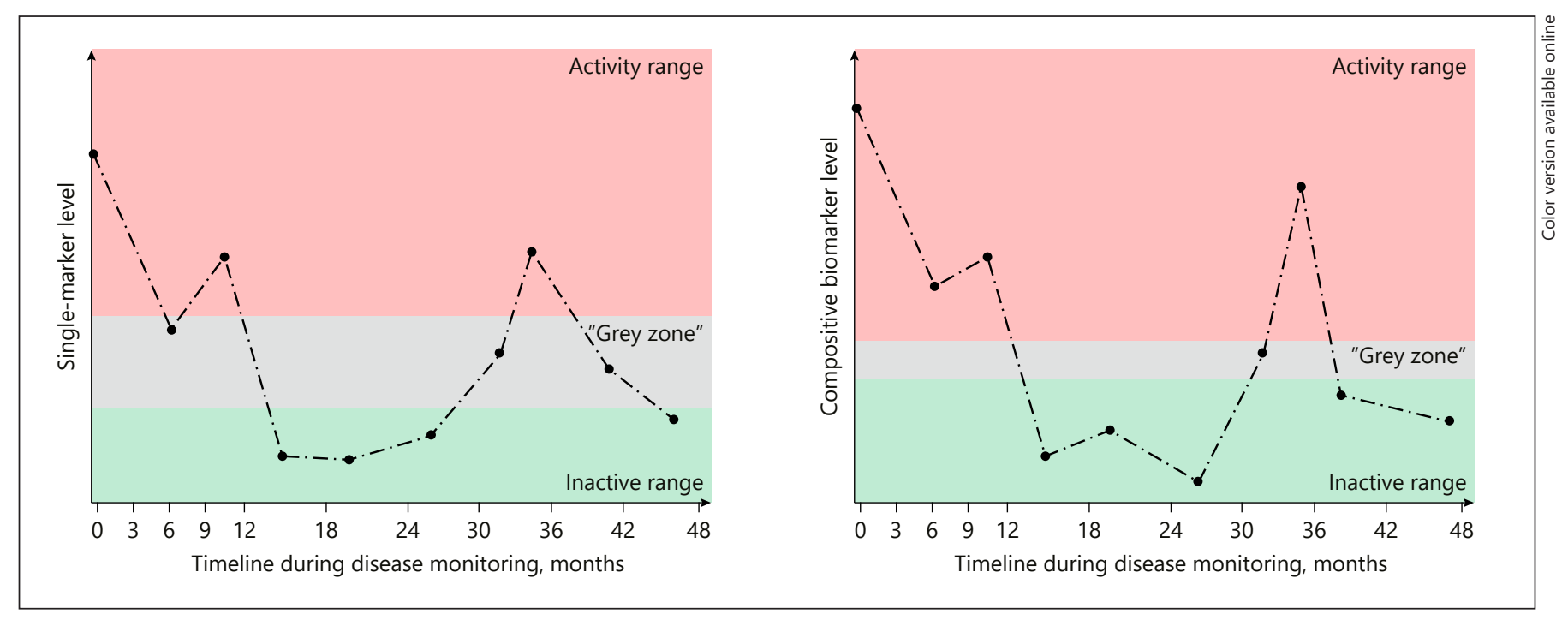

Fig. 2. Improvements provided by composite biomarkers. Careful selection of markers and their integration can optimize the diagnostic accuracy of single biomarkers of disease activity and drastically reduce the blind spot resulted from the "grey zone."

ited benefit over FC or CRP alone in predicting endoscopic activity in CD. A possible explanation for these results is that scores considering patient-reported symptoms might often present subjective biases.

The exclusive integration of objective biomarkers is likely to provide the most reliable results. For instance, an analysis of the serum levels of 10 inflammatory markers involved in IBD pathogenesis reported that the combination of the 4 most predictive biomarkers (serum amyloid A, IL-6, IL-8, and eotaxin-1) was superior to CRP and FC in predicting the presence of endoscopic activity [110]. Similarly, a panel of 7 cytokines (TNF- $\alpha$, IL-12, IL-8, IL-2, IL-5, IL1- $\beta$, and IFN- $\gamma$ ) has been demonstrated a strong predictor of clinical response to anti-TNF induction therapy in UC patients, with a sensitivity of $84.2 \%$ and a specificity of $93.3 \%$ [111]. Likewise, a recent work by Bertani et al. [112] reported that the combined decrease in IL-6 and IL- 8 from baseline to week 6 after introduction of vedolizumab in patients with UC was the most accurate tool to predict mucosal healing at 1 -year endoscopic assessment.

In general, the best strategy is probably to maintain FC as the cornerstone of IBD monitoring and increase its diagnostic accuracy by integrating other laboratory parameters, both at serum and faecal levels [113-117]. For example, the comprehensive evaluation of FC with IL-6 and IFN- $\gamma$ was superior to FC alone in predicting Crohn's post-operative recurrence at 6 months [113]. In addition, the combination of FC with the faecal immunochemical blood test has resulted in higher accuracy for the identification of UC patients at risk of relapse than either of the 2 markers alone [114]. Moreover, integrating FC data with trough levels of drugs could predict loss of response to the medication with higher accuracy than single markers, as demonstrated for IFX trough levels $<2 \mu \mathrm{g} / \mathrm{mL}$ and FC $>250 \mu \mathrm{g} / \mathrm{g}$ [117].

Regarding drug trough levels, their combination with inflammatory biomarkers is certainly a field to expand, as we lack data in this specific topic. An extensive discussion of the isolated relevance of trough levels and therapeutic drug monitoring is beyond the scope of this review.

\section{Conclusion}

To date, except for CRP and FC, none of the other presented markers are routinely tested and used in clinical practice. The reasons behind these results are 2 -fold: first, most of biomarkers have been tested in small clusters of patients and lack validation in large populations; second, technical issues and expensive procedures result in low practicality and scarce access to the proposed assays.

Evidence has shown that FC is currently the most reliable biomarker of intestinal inflammation, particularly when baseline and consecutive measurements are available $[118,119]$. As it is not perfect and its accuracy may 
vary among different clinical scenarios and influencing factors, it is fundamental to start introducing new parameters to implement FC precision.

In our clinical practice, we consider FC as the cornerstone of non-invasive intestinal inflammation assessment. As already reported, it is important to have many consecutive evaluations to provide a correct interpretation of the measurement and monitor the situation. For this reason, we always ask a recent FC level at first outpatient visit at our IBD clinic, even in asymptomatic patients in remission. In addition, we recommend patients transitioned from other centres or resident in the surrounding provinces of Tuscany to routinely perform the test in the same place to eliminate the laboratory variable. However, despite our trust in FC, we often seek confirmation of other biological markers, such as CRP and haemoglobin, and of course stool frequency, consistency, and blood presence. With regard to this, we try to explain to each patient all the "red flags" of their disease both at clinical and biomarker level, in order to promptly react and contact us to move up their follow-up visit if needed.

In the end, the purpose for the research in this field should be to eliminate or at least decrease the "grey zone" of each biomarker (Fig. 2), which could either be reached by improving the sensitivity of detection assays or by integrating together different markers. Therefore, we believe that the validation of non-invasive composite biomarker scores to measure disease activity is an important need for our clinical practice, whose final aim is to reliably manage IBD with less invasive procedures and more empiric decision-making regarding treatment adjustments.

\section{Conflict of Interest Statement}

The authors have nothing to disclose.

\section{Funding Sources}

This work received no sponsored funding.

\section{Author Contributions}

G.D. and T.I. performed the systematic review of the literature and drafted manuscript, tables, and figures. A.G. contributed to the conception and design of the review, provided interpretation of current knowledge, and critically revised the manuscript. All co-authors have approved the final version ahead of submission.

\section{References}

1 Xavier RJ, Podolsky DK. Unravelling the pathogenesis of inflammatory bowel disease. Nature. 2007;448(7152):427-34.

2 Khor B, Gardet A, Xavier RJ. Genetics and pathogenesis of inflammatory bowel disease. Nature. 2011;474(7351):307-17.

3 De Souza HSP, Fiocchi C, Iliopoulos D. The IBD interactome: an integrated view of aetiology, pathogenesis and therapy. Nat Rev Gastroenterol Hepatol. 2017;14(12):739-49.

4 Maaser C, Sturm A, Vavricka SR, Kucharzik T, Fiorino G, Annese V, et al. ECCO-ESGAR guideline for diagnostic assessment in IBD part 1: initial diagnosis, monitoring of known IBD, detection of complications. J Crohns Colitis. 2019;13(2): 144-64.

5 Aronson JK, Ferner RE. Biomarkers: a general review. Curr Protoc Pharmacol. 2017;76: 9.23.1-17.

6 Gomollón F, Dignass A, Annese V, Tilg H, Van Assche G, Lindsay JO, et al. European evidence-based consensus on the diagnosis and management of Crohn's disease 2016: part 1: diagnosis and medical management. J Crohns Colitis. 2017;11:3-25.

7 Melmed GY, Elashoff R, Chen GC, Nastaskin I, Papadakis KA, Vasiliauskas EA, et al. Predicting a change in diagnosis from ulcerative colitis to Crohn's disease: a nested, case-control study. Clin Gastroenterol Hepatol. 2007; $5: 602-8$.
8 Peyrin-Biroulet L, Sandborn W, Sands BE, Reinisch W, Bemelman W, Bryant RV, et al. Selecting therapeutic targets in inflammatory bowel disease (STRIDE): determining therapeutic goals for treat-to-target. Am J Gastroenterol. 2015;110(9):1324-38.

9 Allen PB, Bonovas S, Danese S, Peyrin-Biroulet L. Evolving primary and secondary endpoints in randomized controlled trials leading to approval of biologics and small molecules in IBD: an historical perspective. Expert Opin Biol Ther. 2020;20(2):151-61.

10 Ford AC, Lacy BE, Talley NJ. Irritable bowel syndrome. N Engl J Med. 2017;376(26):256678.

11 Sands BE. Biomarkers of inflammation in inflammatory bowel disease. Gastroenterology. 2015;149(5):1275-e2.

12 Chang S, Malter L, Hudesman D. Disease monitoring in inflammatory bowel disease. World J Gastroenterol. 2015;21(40):1124659.

13 Suk Danik J, Chasman DI, Cannon CP, Miller DT, Zee RY, Kozlowski P, et al. Influence of genetic variation in the $\mathrm{C}$-reactive protein gene on the inflammatory response during and after acute coronary ischemia. Ann Hum Genet. 2006;70(Pt 6):705-16.
14 Henderson P, Kennedy NA, Van Limbergen JE, Cameron FL, Satsangi J, Russell RK, et al. Serum C-reactive protein and CRP genotype in pediatric inflammatory bowel disease: influence on phenotype, natural history, and response to therapy. Inflamm Bowel Dis. 2015; 21(3):596-605.

15 Menees SB, Powell C, Kurlander J, Goel A, Chey WD. A meta-analysis of the utility of Creactive protein, erythrocyte sedimentation rate, fecal calprotectin, and fecal lactoferrin to exclude inflammatory bowel disease in adults with IBS. Am J Gastroenterol. 2015;110(3): 444-54.

16 Solem CA, Loftus EV, Tremaine WJ, Harmsen WS, Zinsmeister AR, Sandborn WJ. Correlation of C-reactive protein with clinical, endoscopic, histologic, and radiographic activity in inflammatory bowel disease. Inflamm Bowel Dis. 2005;11(8):707-12.

17 Sonoyama H, Kawashima K, Ishihara S, Kotani S, Fukuba N, Oka A, et al. Capabilities of fecal calprotectin and blood biomarkers as surrogate endoscopic markers according to ulcerative colitis disease type. J Clin Biochem Nutr. 2019;64(3):265-70.

18 Vermeire S, Van Assche G, Rutgeerts P. The role of $\mathrm{C}$-reactive protein as an inflammatory marker in gastrointestinal diseases. Nat Clin Pract Gastroenterol Hepatol. 2005;2(12): $580-6$. 
19 Saverymuttu SH, Hodgson HJ, Chadwick VS, Pepys MB. Differing acute phase responses in Crohn's disease and ulcerative colitis. Gut. 1986;27(7):809-13.

20 Henriksen M, Jahnsen J, Lygren I, Stray N, Sauar J, Vatn $\mathrm{MH}$, et al. C-reactive protein: a predictive factor and marker of inflammation in inflammatory bowel disease. Results from a prospective population-based study. Gut. 2008;57(11):1518-23.

21 Harbord M, Eliakim R, Bettenworth D, Karmiris K, Katsanos K, Kopylov U, et al. Third European evidence-based consensus on diagnosis and management of ulcerative colitis. Part 2: current management. J Crohns Colitis. 2017;11(7):769-84.

22 Moore AC, Bressler B. Acute severe ulcerative colitis: the oxford criteria no longer predict in-hospital colectomy rates. Dig Dis Sci. 2020; 65(2):576-80.

23 Bitton A, Dobkin PL, Edwardes MD, Sewitch MJ, Meddings JB, Rawal S, et al. Predicting relapse in Crohn's disease: a biopsychosocial model. Gut. 2008;57:1386-92.

24 Consigny Y, Modigliani R, Colombel JF, Dupas JL, Lémann M, Mary JY. A simple biological score for predicting low risk of shortterm relapse in Crohn's disease. Inflamm Bowel Dis. 2006;12(7):551-7.

25 Roblin X, Marotte H, Leclerc M, Del Tedesco E, Phelip JM, Peyrin-Biroulet L, et al. Combination of C-reactive protein, infliximab trough levels, and stable but not transient antibodies to infliximab are associated with loss of response to infliximab in inflammatory bowel disease. J Crohns Colitis. 2015;9(7): 525-31.

26 Tanaka H, Kamata N, Yamada A, Endo K, Fujii T, Yoshino T, et al. Long-term retention of adalimumab treatment and associated prognostic factors for 1189 patients with Crohn's disease. J Gastroenterol Hepatol. 2018;33(5): 1031-8.

27 Regueiro M, Kip KE, Schraut W, Baidoo L, Sepulveda AR, Pesci M, et al. Crohn's disease activity index does not correlate with endoscopic recurrence one year after ileocolonic resection. Inflamm Bowel Dis. 2011;17(1): $118-26$.

28 Sorrentino D, Paviotti A, Terrosu G, Avellini C, Geraci M, Zarifi D. Low-dose maintenance therapy with infliximab prevents postsurgical recurrence of crohn's disease. Clin Gastroenterol Hepatol. 2010;8(7):591-9.

29 Boschetti G, Laidet M, Moussata D, Stefanescu C, Roblin X, Phelip G, et al. Levels of fecal calprotectin are associated with the severity of postoperative endoscopic recurrence in asymptomatic patients with Crohn's disease. Am J Gastroenterol. 2015;110(6):865-72.

30 Mumolo MG, Bertani L, Ceccarelli L, Laino G, Di Fluri G, Albano E, et al. From bench to bedside: fecal calprotectin in inflammatory bowel diseases clinical setting. World J Gastroenterol. 2018;24(33):3681-94

31 Ayling RM, Kok K. Fecal calprotectin. Adv Clin Chem. 2018;87:161-90.
32 Nakashige TG, Zygiel EM, Drennan CL, Nolan EM. Nickel sequestration by the hostdefense protein human calprotectin. J Am Chem Soc. 2017;139(26):8828-36.

33 Røseth AG, Fagerhol MK, Aadland E, Schjønsby H. Assessment of the neutrophil dominating protein calprotectin in feces: a methodologic study. Scand J Gastroenterol. 1992;27:793-8.

34 D'Haens G, Ferrante M, Vermeire S, Baert F, Noman M, Moortgat L, et al. Fecal calprotectin is a surrogate marker for endoscopic lesions in inflammatory bowel disease. Inflamm Bowel Dis. 2012;18:2218-24.

35 Manceau H, Chicha-Cattoir V, Puy H, Peoc'h $\mathrm{K}$. Fecal calprotectin in inflammatory bowel diseases: update and perspectives. Clin Chem Lab Med. 2017;55(4):474-83.

36 Lasson A, Stotzer PO, Öhman L, Isaksson S, Sapnara M, Strid H. The intra-individual variability of faecal calprotectin: a prospective study in patients with active ulcerative colitis. J Crohns Colitis. 2015;9(1):26-32.

37 Reenaers C, Bossuyt P, Hindryckx P, Vanpoucke $\mathrm{H}$, Cremer A, Baert F. Expert opinion for use of faecal calprotectin in diagnosis and monitoring of inflammatory bowel disease in daily clinical practice. United Eur Gastroenterol J. 2018;6(8):1117-25.

38 D'Amico F, Nancey S, Danese S, Peyrin-Biroulet $\mathrm{L}$. A practical guide for faecal calprotectin measurement: myths and realities. J Crohns Colitis. 2020;jjaa093.

39 Rokkas T, Portincasa P, Koutroubakis IE. Fecal calprotectin in assessing inflammatory bowel disease endoscopic activity: a diagnostic accuracy meta-analysis. J Gastrointest Liver Dis. 2018;27:299-306.

40 Gecse KB, Brandse JF, Van Wilpe S, Löwenberg M, Ponsioen C, Van Den Brink G, et al. Impact of disease location on fecal calprotectin levels in Crohn's disease. Scand J Gastroenterol. 2015;50(7):841-7.

41 Kopylov U, Yung DE, Engel T, Avni T, Battat $\mathrm{R}$, Ben-Horin S, et al. Fecal calprotectin for the prediction of small-bowel Crohn's disease by capsule endoscopy: a systematic review and meta-analysis. Eur J Gastroenterol Hepatol. 2016;28:1137-44.

42 Reinisch W, Panaccione R, Bossuyt P, Baert F, Armuzzi A, Hébuterne X, et al. Association of biomarker cutoffs and endoscopic outcomes in Crohn's disease: a post hoc analysis from the CALM Study. Inflamm Bowel Dis. 2020 Sep 18;26(10):1562-1571.

43 Simon EG, Wardle R, Thi AA, Eldridge J, Samuel S, Moran GW. Does fecal calprotectin equally and accurately measure disease activity in small bowel and large bowel Crohn's disease?: a systematic review. Intest Res. 2019; 17:160-70

44 Patel A, Panchal H, Dubinsky MC. Fecal calprotectin levels predict histological healing in ulcerative colitis. Inflamm Bowel Dis. 2017; 23(9):1600-4.
45 Marchal-Bressenot A, Salleron J, BoulagnonRombi C, Bastien C, Cahn V, Cadiot G, et al. Development and validation of the Nancy histological index for UC. Gut. 2017;66(1): 43-9.

46 Geboes K, Riddell R, Öst A, Jensfelt B, Persson $\mathrm{T}$, Löfberg R. A reproducible grading scale for histological assessment of inflammation in ulcerative colitis. Gut. 2000;47(3):404-9.

47 Zittan E, Kelly OB, Kirsch R, Milgrom R, Burns J, Nguyen GC, et al. Low fecal calprotectin correlates with histological remission and mucosal healing in ulcerative colitis and colonic Crohn's disease. Inflamm Bowel Dis. 2015;22(3):623-30.

48 Theede K, Holck S, Ibsen P, Kallemose T, Nordgaard-Lassen I, Nielsen AM. Fecal calprotectin predicts relapse and histological mucosal healing in ulcerative colitis. Inflamm Bowel Dis. 2016;22(5):1042-8.

49 Magro F, Lopes J, Borralho P, Lopes S, Coelho $\mathrm{R}$, Cotter J, et al. Comparison of different histological indexes in the assessment of $\mathrm{UC} \mathrm{ac}-$ tivity and their accuracy regarding endoscopic outcomes and faecal calprotectin levels. Gut. 2019;68(4):594-603.

50 Hart L, Chavannes M, Kherad O, Maedler C Mourad N, Marcus V, et al. Faecal calprotectin predicts endoscopic and histological activity in clinically quiescent ulcerative colitis. J Crohns Colitis. 2019;14(1):46-52.

51 Walsh A, Kormilitzin A, Hinds C, Sexton V, Brain O, Keshav S, et al. Defining faecal calprotectin thresholds as a surrogate for endoscopic and histological disease activity in ulcerative colitis-a prospective analysis. J Crohns Colitis. 2019;13(4):424-30.

52 D'Amico F, Bonovas S, Danese S, Peyrin-Biroulet L. Review article: faecal calprotectin and histologic remission in ulcerative colitis. Aliment Pharmacol Ther. 2020;51:689-98.

53 Naismith GD, Smith LA, Barry SJ, Munro JI, Laird S, Rankin K, et al. A prospective evaluation of the predictive value of faecal calprotectin in quiescent Crohn's disease. J Crohns Colitis. 2014;8(9):1022-9.

54 De Vos M, Louis EJ, Jahnsen J, Vandervoort JG, Noman M, Dewit O, et al. Consecutive fecal calprotectin measurements to predict relapse in patients with ulcerative colitis receiving infliximab maintenance therapy. Inflamm Bowel Dis. 2013;19(10):2111-7.

55 Molander P, Färkkilä M, Ristimäki A, Salminen $\mathrm{K}$, Kemppainen H, Blomster T, et al. Does fecal calprotectin predict short-term relapse after stopping TNFa-blocking agents in inflammatory bowel disease patients in deep remission? J Crohns Colitis. 2015;9(1):33-40.

56 Yamamoto T, Shimoyama T, Umegae S, Matsumoto K. Serial monitoring of faecal calprotectin for the assessment of endoscopic recurrence in asymptomatic patients after ileocolonic resection for Crohn's disease: a long-term prospective study. Therap Adv Gastroenterol. 2016;9:664-70. 
57 Zhulina Y, Cao Y, Amcoff K, Carlson M, Tysk C, Halfvarson J. The prognostic significance of faecal calprotectin in patients with inactive inflammatory bowel disease. Aliment Pharmacol Ther. 2016;44(5):495-504.

58 Colombel JF, Panaccione R, Bossuyt P, Lukas $\mathrm{M}$, Baert $\mathrm{F}$, Vaňásek $\mathrm{T}$, et al. Effect of tight control management on Crohn's disease (CALM): a multicentre, randomised, controlled phase 3 trial. Lancet. 2018;390:277989.

59 Kolho KL, Raivio T, Lindahl H, Savilahti E. Fecal calprotectin remains high during glucocorticoid therapy in children with inflammatory bowel disease. Scand J Gastroenterol. 2006;41(6):720-5.

60 Osterman MT, Aberra FN, Cross R, Liakos S, McCabe R, Shafran I, et al. Mesalamine dose escalation reduces fecal calprotectin in patients with quiescent ulcerative colitis. Clin Gastroenterol Hepatol. 2014;12(11):1887-e3.

61 Essmann J, Keil C, Unruh O, Otte A, Manns MP, Bachmann O. Fecal calprotectin is significantly linked to azathioprine metabolite concentrations in Crohn's disease. Eur J Gastroenterol Hepatol. 2019;31(1):99-108.

62 De Vos M, Dewit O, D’Haens G, Baert F, Fontaine F, Vermeire S, et al. Fast and sharp decrease in calprotectin predicts remission by infliximab in anti-TNF naïve patients with ulcerative colitis. J Crohns Colitis. 2012;6(5): $557-62$.

63 Boschetti G, Garnero P, Moussata D, Cuerq C, Préaudat C, Duclaux-Loras R, et al. Accuracies of serum and fecal S100 proteins (calprotectin and calgranulin $\mathrm{C}$ ) to predict the response to TNF antagonists in patients with Crohn's disease. Inflamm Bowel Dis. 2015;21: 331-6.

64 Reinisch W, Bressler B, Curtis R, Parikh A, Yang H, Rosario M, et al. Fecal calprotectin responses following induction therapy with vedolizumab in moderate to severe ulcerative colitis: a post hoc analysis of GEMINI 1. Inflamm Bowel Dis. 2019;25(4):803-10.

65 Dulai PS, Battat R, Barsky M, Nguyen NH, Ma C, Narula N, et al. Incorporating fecal calprotectin into clinical practice for patients with moderate-to-severely active ulcerative colitis treated with biologics or small-molecule inhibitors. Am J Gastroenterol. 2020;115(6): 885-94.

66 Lamb CA, Mohiuddin MK, Gicquel J, Neely D, Bergin FG, Hanson JM, et al. Faecal calprotectin or lactoferrin can identify postoperative recurrence in Crohn's disease. Br J Surg. 2009;96(6):663-74.

67 Yamamoto T, Shiraki M, Bamba T, Umegae S, Matsumoto K. Faecal calprotectin and lactoferrin as markers for monitoring disease activity and predicting clinical recurrence in patients with Crohn's disease after ileocolonic resection: a prospective pilot study. United Eur Gastroenterol J. 2013;1:368-74.
68 Wright EK, Kamm MA, De Cruz P, Hamilton AL, Ritchie KJ, Krejany EO, et al. Measurement of fecal calprotectin improves monitoring and detection of recurrence of Crohn's disease after surgery. Gastroenterology. 2015; 148(5):938-e1.

69 Papamichael K, Archavlis E, Kyriakos N, Kalantzis C, Drougas I, Konstantopoulos P, et al. P402 Faecal calprotectin but not serum CRP predicts post-operative endoscopic recurrence of Crohn's disease. J Crohns Colitis. 2012;6(Suppl 1):S169.

70 Wright EK, Kamm MA, De Cruz P, Hamilton AL, Ritchie KJ, Keenan JI, et al. Comparison of fecal inflammatory markers in Crohn's disease. Inflamm Bowel Dis. 2016;22(5):108694.

71 Qiu Y, Mao R, Chen BL, He Y, Zeng ZR, Xue $\mathrm{L}$, et al. Fecal calprotectin for evaluating postoperative recurrence of Crohn's disease: a meta-analysis of prospective studies. Inflamm Bowel Dis. 2015;21(2):315-22.

72 Dragoni G, Ding N, Gecse KB, Mansfield JC, Kopylov U, Beaugerie L, et al. The prevention and management of Crohn's disease postoperative recurrence: results from the YECCO/ ClinCom 2019 survey. Eur J Gastroenterol Hepatol. 2020;32:1062-6.

73 Fauny M, D’Amico F, Bonovas S, Netter P, Danese S, Loeuille D, et al. Fecal calprotectin for the diagnosis of bowel inflammation in patients with rheumatological diseases: a systematic review. J Crohns Colitis. 2020;14: 688-93.

74 Kopi TA, Shahrokh S, Mirzaei A, Aghdaei HA, Kadijani AA. The role of serum calprotectin as a novel biomarker in inflammatory bowel diseases: a review study. Gastroenterol Hepatol Bed Bench. 2019;12:183-9.

75 Meuwis MA, Vernier-Massouille G, Grimaud JC, Bouhnik Y, Laharie D, Piver E, et al. Serum calprotectin as a biomarker for Crohn's disease. J Crohns Colitis. 2013;7(12):e678-83.

76 Mosli MH, Zou G, Garg SK, Feagan SG, MacDonald JK, Chande N, et al. C-reactive protein, fecal calprotectin, and stool lactoferrin for detection of endoscopic activity in symptomatic inflammatory bowel disease patients: a systematic review and meta-analysis. Am J Gastroenterol. 2015;110(6):80220.

77 Wright EK. Calprotectin or lactoferrin: do they help. Dig Dis. 2016;34(1-2):98-104.

78 Dai C, Jiang M, Sun MJ, Cao Q. Fecal lactoferrin for assessment of inflammatory bowel disease activity: a systematic review and metaanalysis. J Clin Gastroenterol. 2020;54(6): 545-53.

79 Langhorst J, Boone J, Lauche R, Rueffer A, Dobos G. Faecal lactoferrin, calprotectin, pmn-elastase, crp, and white blood cell count as indicators for mucosal healing and clinical course of disease in patients with mild to moderate ulcerative colitis: post hoc analysis of a prospective clinical trial. J Crohns Colitis. 2016;10(7):786-94.
80 Rubio MG, Amo-Mensah K, Gray JM, Nguyen VQ, Nakat S, Grider D, et al. Fecal lactoferrin accurately reflects mucosal inflammation in inflammatory bowel disease. World J Gastrointest Pathophysiol. 2019;10(5):54-63.

81 Mehta A, Baltimore D. MicroRNAs as regulatory elements in immune system logic. Nat Rev Immunol. 2016;16(5):279-94.

82 Wu F, Guo NJ, Tian H, Marohn M, Gearhart S, Bayless TM, et al. Peripheral blood microRNAs distinguish active ulcerative colitis and Crohn's disease. Inflamm Bowel Dis. 2011; 17(1):241-50.

83 Iborra M, Bernuzzi F, Correale C, Vetrano S, Fiorino G, Beltrán B, et al. Identification of serum and tissue micro-RNA expression profiles in different stages of inflammatory bowel disease. Clin Exp Immunol. 2013;173(2):2508.

84 Oikonomopoulos A, Polytarchou C, Joshi S, Hommes DW, Iliopoulos D. Identification of circulating microRNA signatures in Crohn's disease using the nanostring nCounter technology. Inflamm Bowel Dis. 2016;22(9): 2063-9.

85 Schönauen K, Le N, Von Arnim U, Schulz C, Malfertheiner P, Link A. Circulating and fecal microRNAs as biomarkers for inflammatory bowel diseases. Inflamm Bowel Dis. 2018; 24(7):1547-57.

86 Verdier J, Breunig IR, Ohse MC, Roubrocks $S$, Kleinfeld S, Roy S, et al. Faecal micro-RNAs in inflammatory bowel diseases. J Crohns Colitis. 2020;14(1):110-7.

87 Zahm AM, Hand NJ, Tsoucas DM, Le Guen CL, Baldassano RN, Friedman JR. Rectal microRNAs are perturbed in pediatric inflammatory bowel disease of the colon. J Crohns Colitis. 2014;8(9):1108-17.

88 Thorlacius-Ussing G, Schnack Nielsen B, Andersen V, Holmstrøm K, Pedersen AE. Expression and localization of miR-21 and miR126 in mucosal tissue from patients with inflammatory bowel disease. Inflamm Bowel Dis. 2017;23(5):739-52.

89 Wu LY, Ma XP, Shi Y, Bao CH, Jin XM, Lu Y, et al. Alterations in microRNA expression profiles in inflamed and noninflamed ascending colon mucosae of patients with active Crohn's disease. J Gastroenterol Hepatol. 2017;32(10):1706-15.

90 Fujioka S, Nakamichi I, Esaki M, Asano K, Matsumoto T, Kitazono T. Serum microRNA levels in patients with Crohn's disease during induction therapy by infliximab. J Gastroenterol Hepatol. 2014;29(6):1207-14.

91 Shinzaki S, Iijima H, Nakagawa T, Egawa S, Nakajima S, Ishii S, et al. IgG oligosaccharide alterations are a novel diagnostic marker for disease activity and the clinical course of inflammatory bowel disease. Am J Gastroenterol. 2008;103(5):1173-81.

92 Theodoratou E, Campbell H, Ventham NT, Kolarich D, Pučić-Baković M, Zoldoš V, et al. The role of glycosylation in IBD. Nat Rev Gastroenterol Hepatol. 2014;11(10):588-600. 
93 Šimurina M, de Haan N, Vučković F, Kennedy NA, Štambuk J, Falck D, et al. Glycosylation of immunoglobulin $\mathrm{G}$ associates with clinical features of inflammatory bowel diseases. Gastroenterology. 2018;154:1320-33.

94 Clerc F, Novokmet M, Dotz V, Reiding KR, de Haan N, Kammeijer GSM, et al. Plasma $\mathrm{N}$-glycan signatures are associated with features of inflammatory bowel diseases. Gastroenterology. 2018;155(3):829-43.

95 Vermeire S, Van Assche G, Rutgeerts P. Laboratory markers in IBD: useful, magic, or unnecessary toys? Gut. 2006;55(3):42631.

96 Gabay C, Kushner I. Acute-phase proteins and other systemic responses to inflammation. N Engl J Med. 1999;340(6):448-54.

97 Cioffi M, Rosa AD, Serao R, Picone I, Vietri MT. Laboratory markers in ulcerative colitis: current insights and future advances. World J Gastrointest Pathophysiol. 2015; 6(1):13-22.

98 Cornish JS, Wirthgen E, Däbritz J. Biomarkers predictive of response to thiopurine therapy in inflammatory bowel disease. Front Med. 2020;7:8.

99 Amcoff K, Stridsberg M, Lampinen M, Magnuson A, Carlson M, Halfvarson J. Clinical implications of assay specific differences in $\mathrm{f}$-calprotectin when monitoring inflammatory bowel disease activity over time. Scand J Gastroenterol. 2017;52(3): 344-50.

100 Dulai PS, Peyrin-Biroulet L, Danese S, Sands BE, Dignass A, Turner D, et al. Approaches to integrating biomarkers into clinical trials and care pathways as targets for the treatment of inflammatory bowel diseases. Gastroenterology. 2019;157(4): 1032-e1.

101 Boyapati RK, Kalla R, Satsangi J, Ho GT. Biomarkers in search of precision medicine in IBD. Am J Gastroenterol. 2016;111(12): 1682-90.

102 Verdejo C, Hervías D, Roncero Ó, Arias Á, Bouhmidi A, Lorente R, et al. Fecal calprotectin is not superior to serum C-reactive protein or the Harvey-Bradshaw index in predicting postoperative endoscopic recurrence in Crohn's disease. Eur J Gastroenterol Hepatol. 2018;30(12):1521-7.

103 Bodelier AG, Jonkers D, van den Heuvel T, de Boer E, Hameeteman W, Masclee AA, et al. High percentage of IBD patients with indefinite fecal calprotectin levels: additional value of a combination score. Dig Dis Sci. 2017;62(2):465-72.

104 Sollelis E, Quinard RM, Bouguen G, Goutte M, Goutorbe F, Bouvier D, et al. Combined evaluation of biomarkers as predictor of maintained remission in Crohn's disease. World J Gastroenterol. 2019;25(19):235464.

105 Puolanne AM, Kolho KL, Alfthan H, Ristimäki A, Mustonen H, Färkkilä M. Rapid fecal calprotectin test and symptom index in monitoring the disease activity in colonic inflammatory bowel disease. Dig Dis Sci. 2017;62(11):3123-30.

106 Minderhoud IM, Steyerberg EW, Van Bodegraven AA, Van Der Woude CJ, Hommes DW, Dijkstra G, et al. Predicting endoscopic disease activity in Crohn's disease: a new and validated noninvasive disease activity index (The Utrecht Activity Index). Inflamm Bowel Dis. 2015;21:2453-9.

107 Langhorst J, Elsenbruch S, Koelzer J, Rueffer A, Michalsen A, Dobos GJ. Noninvasive markers in the assessment of intestinal inflammation in inflammatory bowel diseases: performance of fecal lactoferrin, calprotectin, and PMN-elastase, CRP, and clinical indices. Am J Gastroenterol. 2008;103(1):162-9.

108 Cozijnsen MA, Ben Shoham A, Kang B, Choe $\mathrm{BH}$, Choe $\mathrm{YH}$, Jongsma MME, et al. Development and validation of the mucosal inflammation noninvasive index for pediatric Crohn's disease. Clin Gastroenterol Hepatol. 2020;18(1):133-e1.

109 Brand EC, Elias SG, Minderhoud IM, van der Veen JJ, Baert FJ, Laharie D, et al. Systematic Review and external validation of prediction models based on symptoms and biomarkers for identifying endoscopic activity in Crohn's disease. Clin Gastroenterol Hepatol. 2020;18(8):1704-18.

110 Bourgonje AR, von Martels JZH, Gabriëls RY, Blokzijl T, Buist-Homan M, Heegsma J, et al. A combined set of four serum inflammatory biomarkers reliably predicts endoscopic disease activity in inflammatory bowel disease. Front Med. 2019;6:251.

111 Obraztsov IV, Shirokikh KE, Obraztsova OI, Shapina MV, Wang MH, Khalif IL. Multiple cytokine profiling: a new model to predict response to tumor necrosis factor antagonists in ulcerative colitis patients. Inflamm Bowel Dis. 2019;25(3):524-31.

112 Bertani L, Baglietto L, Antonioli L, Fornai M, Tapete G, Albano E, et al. Assessment of serum cytokines predicts clinical and endoscopic outcomes to vedolizumab in ulcerative colitis patients. Br J Clin Pharmacol. 2020;86(7):1296-305.

113 Cerrillo E, Moret I, Iborra M, Pamies J, Hervás D, Tortosa L, et al. A nomogram combining fecal calprotectin levels and plasma cytokine profiles for individual prediction of postoperative Crohn's disease recurrence. Inflamm Bowel Dis. 2019;25(10): 1681-91.

114 Naganuma M, Kobayashi T, Nasuno M, Motoya S, Kato S, Matsuoka K, et al. Significance of conducting 2 types of fecal tests in patients with ulcerative colitis. Clin Gastroenterol Hepatol. 2020;18(5):1102-e5.

115 Loktionov A, Chhaya V, Bandaletova T, Poullis A. Inflammatory bowel disease detection and monitoring by measuring biomarkers in non-invasively collected colorectal mucus. J Gastroenterol Hepatol. 2017; 32(5):992-1002.

116 Karling P, Lundgren D, Eklöf V, Palmqvist $\mathrm{R}$, Hultdin J. Improved monitoring of in- flammatory activity in patients with ulcerative colitis by combination of faecal tests for haemoglobin and calprotectin. Scand J Clin Lab Invest. 2019;79(5):341-6.

117 Roblin X, Duru G, Williet N, Del Tedesco E, Cuilleron M, Jarlot C, et al. Development and internal validation of a model using fecal calprotectin in combination with infliximab trough levels to predict clinical relapse in Crohn's disease. Inflamm Bowel Dis. 2017;23(1):126-32.

118 Yamamoto T, Shimoyama T, Matsumoto K Consecutive monitoring of faecal calprotectin during mesalazine suppository therapy for active rectal inflammation in ulcerative colitis. Aliment Pharmacol Ther. 2015; 42(5):549-58

119 Heida A, Park KT, Van Rheenen PF. Clinical utility of fecal calprotectin monitoring in asymptomatic patients with inflammatory bowel disease: a systematic review and practical guide. Inflamm Bowel Dis. 2017;23(6): 894-902.

120 Lubega J, Davies TJ. A comparison of serum mucoprotein with serum alpha 1 acid glycoprotein, haptoglobin, and alpha 1 antitrypsin assays in monitoring inflammatory bowel disease. Clin Chim Acta. 1990;188(1): 59-69.

121 Biancone L, Fantini M, Tosti C, Bozzi R, Vavassori P, Pallone F. Fecal alpha 1-antitrypsin clearance as a marker of clinical relapse in patients with Crohn's disease of the distal ileum. Eur J Gastroenterol Hepatol. 2003;15(3):261-6.

122 Yilmaz B, Köklü S, Yüksel O, Arslan S. Serum beta 2-microglobulin as a biomarker in inflammatory bowel disease. World J Gastroenterol. 2014;20:10916-20.

123 Maor I, Rainis T, Lanir A, Lavy A. Adenosine deaminase activity in patients with Crohn's disease: distinction between active and nonactive disease. Eur J Gastroenterol Hepatol. 2011;23:598-602.

124 Sajjadi M, Gholamrezaei A, Daryani NE. No association between serum adenosine deaminase activity and disease activity in Crohn's disease. Dig Dis Sci. 2015;60(6): 1755-60.

125 Beyazit Y, Koklu S, Tas A, Purnak T, Sayilir A, Kurt M, et al. Serum adenosine deaminase activity as a predictor of disease severity in ulcerative colitis. J Crohns Colitis. 2012;6(1):102-7.

126 Buisson A, Vazeille E, Minet-Quinard R, Goutte M, Bouvier D, Goutorbe F, et al. Faecal chitinase 3 -like 1 is a reliable marker as accurate as faecal calprotectin in detecting endoscopic activity in adult patients with inflammatory bowel diseases. Aliment Pharmacol Ther. 2016;43(10):1069-79.

127 Aomatsu $\mathrm{T}$, Imaeda $\mathrm{H}$, Matsumoto $\mathrm{K}$, Kimura E, Yoden A, Tamai H, et al. Faecal chitinase 3-like-1: a novel biomarker of disease activity in paediatric inflammatory bowel disease. Aliment Pharmacol Ther. 2011;34(8):941-8. 
128 Pinto-Lopes P, Afonso J, Pinto-Lopes R, Rocha C, Lago P, Gonçalves R, et al. Serum dipeptidyl peptidase 4: a predictor of disease activity and prognosis in inflammatory bowel disease. Inflamm Bowel Dis. 2020.

129 Li T, Chen RR, Gong HP, Wang BF, Wu XX, Chen YQ, et al. FGL2 regulates IKK/NF- $k B$ signaling in intestinal epithelial cells and lamina propria dendritic cells to attenuate dextran sulfate sodium-induced colitis. Mol Immunol. 2020;117:84-93.

130 Stanke-Labesque F, Pofelski J, MoreauGaudry A, Bessard G, Bonaz B. Urinary leukotriene E4 excretion: a biomarker of inflammatory bowel disease activity. Inflamm Bowel Dis. 2008;14(6):769-74.

131 Day AS, Judd T, Lemberg DA, Leach ST. Fecal M2-PK in children with Crohn's disease: a preliminary report. Dig Dis Sci. 2012;57: 2166-70.

132 Czub E, Herzig KH, Szaflarska-Popawska A, Kiehne K, Socha P, Woś H, et al. Fecal pyruvate kinase: a potential new marker for intestinal inflammation in children with inflammatory bowel disease. Scand J Gastroenterol. 2007;42(10):1147-50.

133 Saito S, Kato J, Hiraoka S, Horii J, Suzuki H, Higashi R, et al. DNA methylation of colon mucosa in ulcerative colitis patients: correlation with inflammatory status. Inflamm Bowel Dis. 2011;17(9):1955-65.

134 Tahara T, Hirata I, Nakano N, Nagasaka M, Nakagawa Y, Shibata T, et al. Comprehensive DNA methylation profiling of inflammatory mucosa in ulcerative colitis. Inflamm Bowel Dis. 2017;23(1):165-73.

135 Somineni HK, Venkateswaran S, Kilaru V, Marigorta UM, Mo A, Okou DT, et al. Blood-derived DNA methylation signatures of Crohn's disease and severity of intestinal inflammation. Gastroenterology. 2019; 156(8):2254-e3.
136 Peterson CG, Eklund E, Taha Y, Raab Y, Carlson M. A new method for the quantification of neutrophil and eosinophil cationic proteins in feces: establishment of normal levels and clinical application in patients with inflammatory bowel disease. Am J Gastroenterol. 2002;97(7):1755-62.

137 Husain N, Tokoro K, Popov JM, Naides SJ, Kwasny MJ, Buchman AL. Neopterin concentration as an index of disease activity in Crohn's disease and ulcerative colitis. J Clin Gastroenterol. 2013;47(3):246-51.

138 Nancey S, Boschetti G, Moussata D, Cotte E, Peyras J, Cuerq C, et al. Neopterin is a novel reliable fecal marker as accurate as calprotectin for predicting endoscopic disease activity in patients with inflammatory bowel diseases. Inflamm Bowel Dis. 2013;19(5): 1043-52.

139 Nancey S, Perret-Liaudet A, Moussata D, Graber I, Boschetti G, Renaud B, et al. Urinary neopterin is a valuable tool in monitoring Crohn's disease activity. Inflamm Bowel Dis. 2008; 14(11):1548-54.

140 Thorsvik S, Damås JK, Granlund AV, Flo TH, Bergh K, Østvik AE, et al. Fecal neutrophil gelatinase-associated lipocalin as a biomarker for inflammatory bowel disease. J Gastroenterol Hepatol. 2017;32(1):128-35.

141 Oikonomou KA, Kapsoritakis AN, Theodoridou C, Karangelis D, Germenis A, Stefanidis I, et al. Neutrophil gelatinase-associated lipocalin (NGAL) in inflammatory bowel disease: association with pathophysiology of inflammation, established markers, and disease activity. J Gastroenterol. 2012; 47(5):519-30.
142 de Bruyn M, Arijs I, De Hertogh G, Ferrante M, Van Assche G, Rutgeerts P, et al. Serum neutrophil gelatinase $\mathrm{B}$-associated lipocalin and matrix metalloproteinase-9 complex as a surrogate marker for mucosal healing in patients with Crohn's disease. J Crohns Colitis. 2015;9(12):1079-87.

143 Lippi G, Sanchis-Gomar F. Procalcitonin in inflammatory bowel disease: drawbacks and opportunities. World J Gastroenterol. 2017; 23(47):8283-90.

144 Yarur AJ, Quintero MA, Jain A, Czul F, Barkin JS, Abreu MT. Serum amyloid a as a surrogate marker for mucosal and histologic inflammation in patients with Crohn's disease. Inflamm Bowel Dis. 2017;23(1):15864.

145 Baba R, Yashiro K, Nagasako K, Obata H. Significance of serum sialic acid in patients with Crohn's disease. Gastroenterol Jpn. 1992;27(5):604-10.

146 Teng X, Yang Y, Liu L, Yang L, Wu J, Sun $\mathrm{M}$, et al. Evaluation of inflammatory bowel disease activity in children using serum trefoil factor peptide. Pediatr Res. 2020.

147 Ning L, Li S, Gao J, Ding L, Wang C, Chen $\mathrm{W}$, et al. Tenascin-C is increased in inflammatory bowel disease and is associated with response to infliximab therapy. Biomed Res Int. 2019;2019:1475705.

148 Nikolaus S, Schulte B, Al-Massad N, Thieme $F$, Schulte DM, Bethge J, et al. Increased tryptophan metabolism is associated with activity of inflammatory bowel diseases. Gastroenterology. 2017;153:1504-16.

149 Kim DJ, Jeoun YM, Lee DW, Koo JS, Lee SW. Usefulness of fecal immunochemical test and fecal calprotectin for detection of active ulcerative colitis. Intest Res. 2018; 16(4):563-70. 